\title{
Difficulties Experienced by Caregivers of HIV/AIDS Orphans: A Qualitative Study for Rural-Based Caregivers
}

\author{
Eric Mamukeyani \\ Limpopo Department of Social Development, Luckau One Stop Centre, Sekhukhune District, Polokwane, South Africa \\ Email: luckaudsd@gmail.com
}

How to cite this paper: Mamukeyani, E. (2021) Difficulties Experienced by Caregivers of HIV/AIDS Orphans: A Qualitative Study for Rural-Based Caregivers. Open Access Library Journal, 8: e6721.

https://doi.org/10.4236/oalib.1106721

Received: September 23, 2020

Accepted: June 21, 2021

Published: June 24, 2021

Copyright $\odot 2021$ by author(s) and Open Access Library Inc.

This work is licensed under the Creative Commons Attribution International License (CC BY 4.0).

http://creativecommons.org/licenses/by/4.0/

\section{(c) (i) Open Access}

\begin{abstract}
Caring for HIV/AIDS orphans is a very noble work which is regard as a calling, however it is true that this work comes with various challenges and difficulties for caregivers who provide services to clients especially in rural areas. Now it becomes clear that these difficulties experienced by caregivers of HIV/AIDS orphans are also serious obstacles hindering them from effectively performing their everyday duties in terms of rendering services to the vulnerable children. The difficulties experienced by the caregivers as revealed by this study include physical difficulties such as increased workload, inadequacy of resources, social difficulties such as stigma and behavioural problems of HIV/AIDS orphans, social difficulty such as stress due to the demanding nature of their work.
\end{abstract}

\section{Subject Areas}

HIV

\section{Keywords}

Stigma, Vulnerable, Stress, Orphan, Caregiver

\section{Introduction}

According to Mathebula, Maimela and Ntuli (2020), the Human Immune Virus and Acquired Immune Deficiency Syndrome epidemic has been one of the public health major crises ever since its onset and it has been contributing significantly to high mortality rate across the world [1]. According to report on the AIDS trends made by Avert (2020), South Africa seems to have been hit the most in the world by the HIV/AIDS epidemic whereby it is estimated that 7.7 million 
people are living with HIV representing $14 \%$ of the population. From age15 to 49 years the HIV rate is estimated to be around 20\%, where Blacks (13\%) are the ones most affected by the epidemic compared to whites ( $0.3 \%) .45 \%$ of deaths are related to HIV/AIDS, leaving children orphaned estimated at around 600,000 [2].

The HIV/AIDS epidemic has done a lot of damage to the world by killing many people. It did not only end many lives but also left devastating psychological, social, emotional and financial effects on the families of the affected children whereby they are left destitute and anguished [3]. The burden of caring for these HIV/AIDS orphans by families, therefore, becomes unbearable due to poverty, financial and emotional hardships that come with the roles [4]. In other words, it is a very huge calamity for many families in Africa having to care for orphans living with HIV which is an everyday struggle.

There have been substantial efforts in South Africa in trying to combat the pandemic; the efforts include the provision of ARVs, condoms and health promotion strategies [1]. These efforts have been successful in trying to curb the spread of the virus ever since it emerged because the quality of life has been improved and the death toll due to the HIVAIDS epidemic has been reduced significantly [5].

When the HIV/AIDS epidemic severely hit South Africa leading to mortality rate escalating, the situation and burden of the disease continued to cause a huge strain on the health system of the country. It caused human resource and financial gaps in the health system [6]. As such, in order, to ease the burden of health care facilities in South Africa, the government came up with the home-based care strategy, which seemed to be effective and convenient in terms of meeting the health needs of people living with AIDS and other chronic diseases [7].

Zikhathile and Atangana (2018) accentuate certain duties done by home-based caregivers in rendering services such as caring for bedridden patients at home, psychosocial support, physical care, health and nursing care, domestic chores, supervising of treatment, referring patients to health care facilities, bereavement counselling and supporting orphans [7]. This method is recognized as a primary health care method and it is reported to be effective in terms of reducing the pressure to deliver health care services nearer to patients at a home-based level. However, convenient as it might sound to ease the pressure in the health system it is also said to be difficult to the caregivers because they experience numerous challenges in the process hence the study was conducted to explore more these challenges [6].

\section{Reviewing Literature}

\subsection{The Plight of HIV/AIDS Orphans}

A child is defined as someone under the age of 18 [8]. Section 28 (3) of the South African Constitution stipulates "...child' means a person under the age of 18 years" [9]. However, a definition of an orphan varies from country to country 
but the common elements include; age (being under 18 years) and the death of both parents regardless of how they died [10].

In South Africa, orphans are regarded as children in need of care and protection and are also vulnerable (OVC) according to Section 150 (1) of South Africa Children's Act 38 of 2005 [11]. This means that they deserve psychosocial services from state and care by families or volunteers who would want to assume parental roles and provide for their basic needs in terms of Section 28 (1) of the Constitution of the Republic of South Africa. Basically, AIDS orphans are those children who have lost either one or both parents due to the AIDS epidemic. The HIV/AIDS orphans are also included in the category of orphaned vulnerable children (OVC) and they qualify to receive assistance from the state and significant others [12].

Orphanhood is a very huge problem in the whole world, particular South Africa as it has many HIV/AIDS orphans living in dire poverty because their biological parents are dead [13]. It is inconceivable to realize that the overwhelming number of HIV/AIDS orphans is being looked after by either one parent; elderly grandparents who also need care and support, or with poor relatives who also experience hardships in meeting their developmental, health and social needs. This means that life becomes extremely hard for AIDS orphan to live [14]. These HI/VAIDS orphans often experience psychological, social and emotional hardships in the process. In other words, these orphans are left to face the storm of hardships of life because of the devastating effects of the HIV/AIDS epidemic [15].

The situation of orphans in South Africa has been there for a long time, but it escalated when the HIV/AIDS epidemic reached its peak on infection and death toll during late 1999 and the year 2000 [2]. In fact, the pandemic had a devastating turmoil on the citizens of SA since the time of its peak [16].

Pretorius (2014) argues that since the onset of the HIV/AIDS epidemic more than 25 million people lost their lives globally, and it resulted in an unbearable trauma for these families who experienced loss [3]. In Sub-Saharan Africa, the HIV/AIDS epidemic made more than 12 million children orphaned and vulnerable as well as living in poverty. In South Africa, the number of children orphaned and those made vulnerable by HIV and AIDS has reached a huge number of approximately 600,000 with an infection rate of 7.7 million [2].

The South African government started to pay more attention to the HIV/AIDS epidemic in 1994 after the African National Congress came into power. The government started to devise means and strategies to try to combat the epidemic [2]. These ways and strategies include health education through awareness and preventive methods. The belief behind these methods was that it was a way in which the epidemic could be contained from spreading further, in other words, the more knowledge people had about the virus the more they were able to practice safe and healthy lifestyle which could curb the spread of the virus [16].

In responding to the OVC crisis, the South African government came up with 
its strategies during the year 2005. Department of Social Development (DSD) came up with a blue-print which led to the development of policy framework in dealing with the situation as it is the one entrusted with the needs and protection of children [17]. The key strategies in this strategic plan encompassed the following; strengthening the capacity of families to care for OVC, mobilizing community-based responses for care, support and protection of OVC, ensuring that legislation, policy, and programmers were in place to protect the most vulnerable children, ensuring access to essential services for OVC, increasing awareness and regarding OVC issues, and engaging the business community to actively support OVC [18].

Responding to the needs of OVC in South Africa is rooted in the constitution of the Republic of South Africa, Section 28 which was written specifically for the protection and upholding of children's rights. The idea is congruent or it is compatible with the subsequent Children's Act 38 of 2005 which elaborates more on the application and endorsement of children's rights and services. The Constitution served as root on the development of regulations and policies to respond to the needs of children, but the introduction of the Children's Act 38 of 2005 expanded Section 28 of the Republic of South Africa. All the interventions and services to OVC are guided by the children's act 38 of 2005 [17].

The Department of Social Development is at the forefront in responding to the psychosocial needs of AIDS orphans. The Department of Social Development is one ministry but different segments such as the South African Social Security Agency (SASSA) which is responsible for capturing and providing social grants, Social services (Social workers, community developers, home-based caregivers, child and youth care workers) who are advocates and custodians of children's rights [5]. All these segments in the departments have a pivotal role to play in ensuring the care and protection of children, especially social workers who identify and assess the needs of children through working with community practitioners and other stakeholders and link them with the relevant service providers like SASSA in eradicating and alleviating poverty by providing social grants [17].

The Department of Social Development does more than just to ensure the provision of social grants and alleviation of poverty. It is at the forefront, it ensures that these needy children are well cared for as the constitution stipulates the provision of care and support to orphans and other children made vulnerable by HIV and AIDS [7]. Among all the Social Development officials, social workers are the ones who are the primary service providers of the children in need. This means that they are indispensable professionals in terms of safeguarding the rights of children. They work with other stakeholders in identifying the children in need of care and protection as well as to provide necessary to them [19].

The Department of Social Development took the initiative to start community-based drop-in centres where children are provided with food and also assisted with school work and life skills programmes. It also started a national fos- 
ter care and adoption system to assist orphans to have families as alternative care and legal placement. It also developed a national database of orphans and vulnerable children (OVC); all these programmes aim to assist OVC to have access to social grants, health treatment, food, skills training and psychosocial support. [5].The government is not alone in fighting this conundrum, it partners with non-government organizations which are there to assist such as religious organizations [12].

\section{2 .The Impacts of HIV/AIDS on Children}

It is a fact that the HIV/AIDS epidemic took many lives leaving a quite number of children orphaned and destitute, and the worst part is that some orphans are living with HIV [13]. This exacerbates the situation because the affected families will have to cope with the calamity of raising HIV/AIDS orphans which becomes extremely hard for them having to meet the psychosocial, and health needs of these children [2]. Worst of all they experience economic hardships where hunger and poverty become their biggest calamities [8]. Stigma and discriminations are other disturbing impacts in the lives of HIV/AIDS orphans and their families especially in communities and schools where there is a little knowledge about the epidemic [10]. Some AIDS orphans are not only affected by the death of their parents, but they are also infected and living with HIV. As such, they deserve serious health care services to ensure that they live and survive well [13].

\section{Research Methodology}

\subsection{Research Approach and Design}

The study followed a qualitative study research approach because it sought to focus on the explanations and views regarding the difficulties experienced by the caregivers of HIV/AIDS orphans [20]. It also followed the exploratory and descriptive research design which enabled the researcher to delve more into the experiences of caregivers [7]. The exploratory design was followed to collect data and gain more insight about the difficulties of HIV/AIDS orphans, the contextual research design was used to study the phenomenon in a natural context and how it affected the HIV/AIDS orphan caregivers, and the descriptive design was used to describe these difficult experiences of AIDS orphan caregivers [21].

\subsection{Study Setting}

The study was conducted at a religious organisation called Parish of Ndzhelele HIV/AIDS response. The organisation is located in Raliphaswa village at Ndzhelele, Makhado municipality, within Vhembe District in Limpopo province, South Africa [22].

The organization is a religious initiative funded by the South African Catholic Bishop's Conference (SACBC). It falls under a Catholic initiative called Choose to Care which is a commitment to combat HIV/AIDS in Southern African countries like Namibia, Swaziland, Botswana and Lesotho. This initiative was established in 
2001 whereby it was successful in establishing home-community-based care organizations focusing on providing medical, psychosocial and educational support for vulnerable and orphaned children. The psychosocial services rendered to HIV/AIDS orphans focused on the holistic approach in terms of thoughts, emotions and behaviour as well as social experiences involving relationships, and culture [14].

The Parish of Ndzhelele organisation had been existing for 2 years during the time of the study; where there were only 06 full-time caregivers by then. It also had 370 orphans registered under the programme and was being offered health, and psychosocial services in a home-based environment [22].

\subsection{Population and Sampling Techniques}

The study targeted caregivers of HIV/AIDS orphans working in rural areas. The caregivers were working for an non-government organization (NGO) in Ndzhelele area. The convenient (non-probability) sampling method was used to select Parish of Ndzhelele HIV/AIDS response unit in Raliphaswa village, Limpopo province in South Africa. The reason for using convenience sampling was because the organization was easily available at the time and it suited the time frame of the study confined by the University of Venda for social work degree purpose [23]. A simple-random (probability) sampling was also used to select participants in the organization who formed part of the sample [24].

According to the University's limit, the number of participants was confined to 05 but the organization had 06 full-time caregivers who had the same equal chances of being included in the sample because they all had 1 to 2 years working experience as per criteria of inclusion of the study, therefore simple random sampling method was necessary to select the 05 participants from the 06 [25].

In terms of the demographic information of participants who participated in the study, the participants were 05, 01 male and 04 females between the ages of 30 to 45 . All of the participants were entrusted with a certain number of orphans to provide care to which ranged from 13 to 17 . The participants had 1 to 2 years of working experience in the organization.

In applying the simple-random sampling, the researcher then wrote 06 small papers with the 05 written yes and 01 written no, they were then mixed in the bowl and every respondent to pick theirs randomly. Those that were selected into the sample were considered participants of the study but the one who was not selected was encouraged to remain calm and to hope that the other colleagues would represent her views in the study [21].

\subsection{Data Collection Method}

A semi-structured interview was used to collect data whereby open-ended questions were asked to participants and follow up questions were asked where necessary. The interview schedule was used to guide the interviews of participants in order to meet the objectives of the study. The main research question of the 
study was, what kind of difficulties do HIV/AIDS orphan caregivers experience in their work? [24].

\subsection{Data Analysis}

Data analysis refers to the process of systematically arranging the interview transcripts, field notes and other materials that the researcher received from participants to understand them and be able to present the findings [25].

For the study, data were analysed using thematic data analysis steps by Clarke and Braun (2013) [27]. The steps involve; 1) Familiarizing oneself with data 2) Coding of data 3) Searching for themes 4) Reviewing themes 5) Defining and naming the themes as well as 6) Writing the research report.

In terms of analysing data, audio-recorded interviews were listened to several times; they were then transcribed from the audio recording into a script for easy analysis. Thereafter coding began whereby the scripts were read several times. This means that the interviews were highlighted on what appears to be major codes in the interviews. The codes were then marked and sorted into themes and sub-themes using mind maps [26].

After the themes and sub-themes had been identified, they were searched if ever they fell under they answered the main objectives. In other words, they were clarified to ensure that they match the objectives of the study. The themes were analysed in to find out their meaning. They were then categorized and named so that they would answer the objectives of the study [26]. Scientific literature was used to interpret for a wider meaning of data. After the analysis was done data were presented in a full research report which was submitted to the University of Venda library.

\subsection{Trustworthiness of the Study}

In terms of the trustworthiness of the study, the researcher ensured credibility, transferability, dependability, and conformability by doing the following; conducting debriefing session before the actual data collection session where everything concerning the nature of the study, ethics and rights of the participants were explained plainly to the participants. The participants were also encouraged to voluntarily join the study [25].

All the participants responded to the same questions being asked unless probing was necessary. The interviews were also recorded using a computer device which was saved and transcribed. Data was analysed objectively based on the responses given by the participants [27].

The research methodology was demonstrated on how they were applied in the research report and how data were collected and transparent step by step. The research study was also supervised by qualified personnel who is well versed in research [23].

The research report was compiled and submitted to the University of Venda for Social work degree purposes as a mini-dissertation. There is also a record of 
all interviews, transcripts, and documents of collected data. These records were kept in safely and confidentially and were used only for academic purposes [24].

\subsection{Ethical Considerations}

The permission to conduct the research study was granted by the University of Venda based in Limpopo in South Africa to submit for the Bachelor of Social Work degree for the 2012 academic year. Written permission was also granted by the head office of Parish of Ndzhelele HIV/AIDS response and Catholic Institute of South Africa [24].

The participants were also fully informed of their rights and the nature of the study for which they gave permissions to freely participate without coercion or deception. The participants voluntarily joined the study after they understood the nature of the study and they were neither forced nor coerced to join the study. Their privacy was respected as their information was kept confidential. No name was disclosed, only alphabets were used as pronouns to protect their identity in the dissertation report [27].

\section{The Findings and Discussion of the Study}

\section{Theme 1: Physical difficulties experienced by caregivers of HIV/AIDS or-} phans

\section{Sub-theme 1.1: Increased workload}

The study found that participants were not happy about the increased workload they had to deal with on daily basis. All the participants indicated that they were overburdened with chores when providing care to HIV/AIDS orphans. They further indicated that these chores made the job more difficult for them. For example, Respondent A said "To make sure that HIV/AIDS orphans receive food, clothes, shelter as well as medication" whereas the other participants said that making home chores for the children as part of their difficult physical activities such as cleaning, cooking, washing dishes and even to provide treatment to HIV/AIDS orphans.

It seems that the work of these caregivers is like that of a nursing work, but done in a home setting environment. It involves rendering health care services to sick or injured orphans, physical care, psychological support such as counselling, domestic chores such as fetching water and cleaning and laundry, spiritual support such as prayer, referring the sick orphans to clinics, offering bereavement counselling to the ones who have lost their loved ones, providing food parcels to them, and offering life skills programmes [7]. All this type of activities are bound to make the caregivers feel overburdened in their work and causes fatigue as well as extreme exhaustion. In fact anyone work that involves caring for people is inevitably burdensome in nature hence the caregivers indicated that they were overburdened by their work [6].

Sub-theme 1.2: Inadequacy of resources

The study found that the caregivers were experiencing problems with regard 
to the inadequacy of resources while rendering services to HIVAIDS orphans [26]. In fact, the inadequacy of these necessary resources such as hand gloves impeded them from actually providing services as required to the HIV/AIDS orphans. Respondent B said "it affects me because I have to protect myself from the wounds they may have when washing HIV/AIDS orphans", and Respondent $\mathrm{D}$ added that "we find that we do not have gloves which means it is not safe to touch these kids with naked hands".

The study also found that the caregivers also travelled long distances and sometimes by foot which increased physical pressure for them while delivering services to these HIV/AIDS orphans. Respondent E said, "It affects me because I have to travel a long distance and check on these kids, if ever they get sick I have to travel back and forth sometimes".

It is a reality that there is still a huge challenge for all the home-based carers across the country, and their plight is generally known to the public. In fact, the inadequacy of resources are still a huge problem in the South African health care system. Many home-based care workers across the country still travel by foot or take a taxi when they conduct home visits, as a result this causes them a tremendous physical fatigue when doing their work [18].

One of the biggest challenges in South African service deliver is the lack of or inadequacy of resources, especially for non-government organizations (NGOs). This inadequacy of resources has always been an obstacle in the effective rendering of psychosocial services to the people in need [18]. In fact, the motive of responding for responding to the needs of these orphaned and vulnerable children (OVC) by the state and the private sector is always good and commendable but the challenge of inadequacy of resources remains a huge obstacle to meet the desired goals as there is a huge influx of orphans which continue to rise in SA due to HIV/AIDS epidemic. In other words this influx situation creates a huge demand which cannot be fully met due to the shortage of funds [2].

The caregivers also indicated that they were somehow exposed while doing their work or they were at risk because they did not have adequate protective measures such as hand gloves. It is very imperative to note that the Occupational Health and Safety Act 85 of 1993 stipulates plethora of obligations and responsibilities that ought to be fulfilled by the employer as well as responsibilities of the employees or workers to ensure safety at work [28]. The purpose of this Act is to ensure that employees and workers are protected from anything that may harm their health and wellbeing, and it binds the employers to ensure that they provide necessary protection for employees or workers in general. This means that it is vital everywhere as an employer to take necessary steps to ensure that workers are not exposed to harmful situations that may endanger their lives [7].

Theme 2: Social difficulties experienced by caregivers of HIV/AIDS orphans

Sub-theme 2.1: Stigma

The study found that the HIV/AIDS orphan caregivers experienced stigma as 
a difficulty when rendering services to HIV/AIDS orphans. Respondent A said, "Some people think that I am HIV positive, but I do not care about it". Respondent B said, "people think I am positive and I am also suspected by my family that I am positive." It is evident that stigma is an inevitable social difficulty experienced by these HIV/AIDS caregivers while doing their work. The worst part is that even their own families tend to stigmatize them. The HIV/AIDS orphans automatically suffer stigma and discrimination because of their known status, but it is absolutely inconceivable to note that even the caregivers suffer the same experience as Respondent D said: "people think that I am infected because of the care I give to these kids."

Clair (2018) defines Stigma as an attribute which conveys a devaluated stereotype or an attribute which is deeply discrediting [29]. Stigma is an inevitable reality to deal with by people who live with HIV/AIDS, and it is fact that not even the caregivers of these HIV/AIDS orphans are immune to it; in fact, they are susceptible to AIDS stigma by the community, families of these children and their own families at home. Furthermore, stigma is something that they have to go through because many people still don't have adequate knowledge about the virus and its nature especially in the rural areas [30]. Sometimes this stigmatization is caused by the superstitious beliefs such as a misconception that HIV/ AIDS is often associated with evil and witchcraft. In addition, this misconception further alludes that if someone has HIV the person is going to die from the disease. This shows that many rural communities are still lacking the necessary information to understand about the nature of HIV/AIDS and its transmission [16].

\section{Sub-theme 2.2: Behavioural problems of HIV/AIDS orphans}

The study found that misbehaviour of HIV/AIDS orphans became another problematic difficulty for caregivers. Some of the orphans were sometimes denial of their situation as reported by the participants. In fact, they were trivializing their situation and taking it for grunted [32] [30], Respondent E said " $A I D S$ orphans are stubborn and denial about their problem. They are mostly angry and blame others for their situation". Respondent D said "most of the orphans fail to understand their situation" whereas Respondent A said, "it pains me so much when an aids orphan falls in love with a child who is not positive". As a result, the caregivers suffered humiliation and discrimination due to the inappropriate behaviour of these AIDS orphans. Respondent B said "they behave badly and they hide when I visit", Respondent C said, "when I visit them they hide and when I ask them why they hide they give lame excuses".

According to a study done by Hlatywayo, Zimondi and Taurai (2015), the HIV/AIDS orphans especially the teenage ones, tend to disrespect and mistreat the caregivers. They are also disobedient and undisciplined. They disregard the services necessary being rendered to them; they are often disrespectful and abrasive to their caregivers. Now, this causes a huge problem for caregivers because they are being hindered to successfully render services [31]. 
Ganga and Mphalala (2013) point out that the orphans' behaviour can be attributed to Erick Erikson's theory of identity versus role confusion stage ranging from ages 13-19 years of adolescence. What happens in this stage is that young adults start to engage in sexual identity and gender roles confusion. In other words, this confusion is inevitable in this stage. They try to find out who they are and what they are capable of doing, so the problems of peer pressure and challenged self-identity and sexuality issues become central leading to more confusion and misbehaviour [15].

Theme 3: Psychological difficulties experienced by caregivers of HIV/ AIDS orphans

\section{Sub-theme 3.1: Stress}

The study found that the caregivers of HIV/AIDS orphans were experiencing stress as an emotional difficulty in their work. There are a plethora of factors which caused them stress at their work such as having to give the HIV/AIDS orphans health medication when they were reluctant to take; Respondent B said; "it is very much stressful to see these children in need of care". Respondent D said, "It is very much stressful when the aids orphans refuse to take medication and they default."

It looks like caring for these HIV/AIDS orphans is cumbersome and demanding in nature as it requires not only skills but a heart as well, as such it contributes greatly to stress daily. The reason why the work becomes stressful for caregivers is because some HIV/AIDS orphans think that the services provided to them aren't important in a way that they become reluctant and rude to the caregivers who are there to help them [31]. Respondent A said: "it does not affect me that much but it pains me a bit when I see aids orphans being reluctant to take medication." Respondent B said, "I worry a lot when I am at home whether they are fine or not".

Shahsavarani, Abadi and Kalkhoran (2015) define stress as a feeling of mental pressure and tension [32]. However, stress various as there is positive stress which can motivate someone to do something good and there is negative stress which is harmful to one's health. This high level of negative stress has a hugely detrimental effect on the health of an individual; it has a potential to harm both physical and mental wellbeing of a person [33]. Now this job is a home nursing kind of work which requires the caregivers to do lots of chores, provide health care and psychosocial support services; as result stress is an inevitable emotional phenomenon which every caregiver is prone to experience. Other feelings that are associated with this type of emotional difficulty include despair and excessive emotional exhaustion due to the hardness of the nature of work [26]

\section{Summary of the Findings}

The study discovered that the difficulties experienced by caregivers of HIV/ AIDS orphans which were classified under three themes namely physical difficulties; increased workload and inadequacy of resources, social difficulties such 
as stigma and behavioural problems of HIV/AIDS orphans, and emotional difficulty such as stress. These difficulties actually hindered them from effectively rendering the services to HIV/AIDS. They were actually burdened by the workload as they had to do lots of chores for the HIV/AIDS orphans during their routine work. They experienced stigmatization from the community and their own families. They experienced resistance and bad attitude from some HIV/ AIDS orphans when rendering services which exacerbated their stress. There was a shortage of resources such as transport and personal protective equipments like gloves which affected their health and wellbeing while rendering services to the HIV/AIDS orphans.

\section{Recommendations of the Study}

The Department of Social Development must be actively involved in rendering necessary support to the NGOs in rural areas as the HIV/AIDS orphans caregivers indicated stress and demotivation to do their work. They must receive extra emotional support from local social workers because their work is demanding and emotionally draining in nature. Furthermore, they need to have a strengthened support and counselling system in place to alleviate their stress. This means that the organizations ought to establish a very strong support system for them, by linking them with social workers who can provide professional counselling and emotional support.

There must be enough and robust campaign which can assist the rural communities to comprehend and construe the nature of the epidemic. In other words, social workers can play a pivotal role in terms of easing the burden of HIV/AIDS orphan caregivers in rural areas by giving relevant to information to assist in the fight.

The Department of Social Development must also improve the communitybased systems or children's homes to accommodate these children who are not safe at home. In other words, the government must improve its homes structure because there is a shortage of children's homes and Child Youth Care Canters in South Africa to accommodate the overwhelming number of the needy children who seek alternative care and protection.

The Department of Health must also be actively involved in rendering support services to assist such NGOs by providing adequate funds, PPEs and support. The organisations must try to ensure that the caregivers are safe when doing their work by ensuring that there is adequate provision of PPEs in terms of Section 8(1) of the Occupational Health and Safety Act 38 of 1993. There must also be adequate funding for these NGOs in order to reduce the burden of rendering services to the HIV/AIDS orphans. There must also be substantial health care support services for HIV/AIDS orphans in place. In fact, the health care system of South Africa must strengthen the OVC policy and response so that it focuses more on children's dilemma. In other words, it must give priority to the health of the sick HIV/AIDS orphans because they need more health care services. 


\section{Conclusion}

This study revealed that voluntary caregivers of HIV/AIDS orphans experienced a variety of difficulties at their work such as stigma, humiliation, and shortage of resources, low wage, too much workload, and stress. These difficulties are often a challenge to their daily work and as such, they require rigorous assistance from the government especially the Department of Health and Social Development. The health system of the country needs to give these orphans a priority and make the job of HIV/AIDS orphan caregivers more convenient. There is still much to be done to resolve the problem of caring for HIV/AIDS orphans. This study was limited because the time was not enough to cover all the NGOs and it was limited only to the caregivers as managers were not part of the study. The suggestion is that future researchers should look into more issues of this topic, perhaps also research the organization's difficulties and orphans experiences living with HIV. Or also do a quantitative study with organizations around the area or district and be able to come up with more objective findings.

\section{Conflicts of Interest}

The author declares no conflicts of interest regarding the publication of this paper.

\section{References}

[1] Mathebula, R.L., Maimela, E. and Ntuli, N.S. (2020) The Prevalence of Selected Non-Communicable Disease Risk Factors among HIV Patients on Anti-Retroviral Therapy in Bushbuckridge Sub-District, Mpumalanga Province. MBC Public Health, 20, Article No. 247. https://doi.org/10.1186/s12889-019-8134-X

[2] (2020) HIV and AIDS in South Africa Avert. https://www.avert.org

[3] Pretorius, E. (2014) Loss, Grief and Bereavement: The Experiences of Children in Kinship Foster Care. Social Work Journal, 46, 469-485.

https://doi.org/10.15270/46-4-153

[4] UNAIDS (2007) HIV/AIDS and STI Strategic Plan for South Africa 2007-2011.

[5] Pocket to Guide to South Africa 2011/12. Social Development. https://www.gcis.gov.za

[6] Lekganyane, M.R. and Alpaslan, N. (2019) Suggestions by Home-Based Caregivers Caring for People Living with HIV and AIDS on How Social Workers Could Support Them in Managing Their Work-Related Challenges. Social Work Journal, 55, 140-157. https://doi.org/10.15270/55-2-712

[7] Zikhathile, T. and Atagana, H. (2018) Challenges Facing Home-Based Caregivers in the Management of Health Care Risk Waste. International Journal of Environmental Research and Public Health, 15, 2700. https://doi.org/10.3390/ijerph15122700

[8] (2019) UNICEF Annual Report. For Every Child, Reimagine. https://www.unicef.org/reports/annual-report-2019

[9] (2008) Constitution of the Republic of South Africa. Juta Publishers, Cape Town.

[10] Smart, R. (2003) Policies for Orphans and Vulnerable Children: A Framework for Moving Ahead. 
[11] (2008) Children's Act 38 of 2005. Juta Publishers, Cape Town.

[12] UNAIDS (2006) A Faith-Based Response to HIV in Southern Africa: The Choose to Care Initiative. https://www.unaids.org

[13] Dewagt, A. (2004) Orphans and the Impact of HIV/AIDS in Sub-Saharan Africa. Food, Nutrition and Agriculture No. 34. https://www.researchgate.net/publication/266160962

[14] Mwowa, T. and Pillay, J. (2015) Psychosocial Support for Orphans and Vulnerable Children in Public Schools: Challenges and Intervention Strategies. South African Journal of education, 35, 1-9. https://doi.org/10.15700/saje.v35n3a1092

[15] Ganga, E. and Maphalala, M.C. (2013) Double Orphanhood: A Psychosocial Barrier to Assimilation of Schemes in Child-Headed Households. Mediterranean Journal of Social Sciences, 4, 499-511. https://doi.org/10.5901/mjss.2013.v4n13p499

[16] Cichocki, M.R.N. (2020) History of the HIV in South Africa. https://www.verywellhealth.com/hiv-around-the-world-south-africa-48673

[17] Hlatywayo, L., Zimondi, F. and Taurai, N. (2015) Challenges of Copying with Orphans and Vulnerable Children at Household Level: A Caregivers Perspective. International Journal of Scientific and Research Publications, 5, 1-11.

https://www.researchgate.net/publication/335003919

[18] Framework for Social Welfare Services. https://www.dsd.gov.za/index.php/documents/category/20-frameworks

[19] Sebastian, B. and Byenkya, T. (2008) AMREF South Africa Sekhukhune and Umkhanyakude OVC Programme. https://www.measureevaluation.org/

[20] Dhavaleshwar, C.U. (2016) The Role of Social Worker in Community Development. International Research Journal of Social Sciences, 5, 61-63.

[21] O'Leary, Z. (2017) The Essentials Guide to Doing Your Research Project. 3rd Edition, Sage Publishers, Thousand Oaks.

[22] Kumar, R. (2014) Research Methodology: A Step by Step Guide for Beginners. 4th Edition, Sage, London.

[23] Mamukeyani, E. (2012) Difficulties for Voluntary Caregivers of AIDS Orphans. The University of Venda, Thohoyandou (Degree Thesis).

[24] Saunders, M., Lewis, D. and Thornhill, A. (2012) Research Methods for Business Students. 6th Edition, Pearson Education Limited, London.

[25] Devlin, A.S. (2018) The Research Experience: Planning, Conducting, and Reporting Research. Sage publishers, London.

[26] Bertram, C. and Christiansen, I. (2014) Understanding Research: An Introduction to Reading Research. Van Schaik, Pretoria.

[27] Clarke, V. and Braun, V. (2013) Teaching Thematic Analysis: Overcoming Challenges and Developing Strategies for Effective Learning. The Psychologist, 26, 120-123.

[28] Xia, L. and Kongsuwan, W. (2020) Factors Relating to Nurses' End-of-Life Care. Journal of Biosciences and Medicines, 8, 189-200.

https://doi.org/10.4236/jbm.2020.86018

[29] Occupational Health and Safety Act 85 of 1993.

https://www.gov.za/documents/occupational-health-and-safety-act?gclid=Cj0KCQj w16KFBhCgAIsALB0g8LMXvUFw 5OoIyMI9zXjVquIrOVE3stxIRWsYxX aXq1g nln07 Sg8aAuZPEALw wcB

[30] Shahsavarani, A.M., Abadi, E.A.M. and Kalkhoran, M.H. (2015) Stress: Facts and Theories through Literature Review. International Journal of Medical Reviews, 2, 230-241. 
[31] Clair, M. (2018) Stigma: Forthcoming in Core Concepts in Sociology.

[32] Makufa, S.C., Kisiyombe, D., Miller, N. and Barkey, N. (2017) Empowering Caregivers of Orphans and Vulnerable Children in Swaziland. African Journal of AIDS Research, 16, 355-363. https://doi.org/10.2989/16085906.2017.1387579

[33] Toussaint, L., Shields, G.S., Dorn, G. and Slavich, G.M. (2016) Effects of Lifetime Stress Exposure on Mental Health and Physical Health in Young Adulthood: How Stress Degrades and Forgiveness Protects Health. Journal of Health Psychology, 21, 1004-1014. https://doi.org/10.1177/1359105314544132 